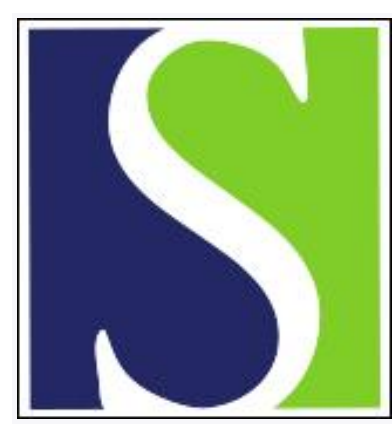

Scand J Work Environ Health 1995;21(5):376-381

https://doi.org/10.5271/sjweh.52

Issue date: Oct 1995

Risk assessment methodologies for carcinogenic compounds in indoor air

by Nexø BA

Key terms: benzene; cancer; tetrachloroethylene; trichloroethylene; vinyl chloride

This article in PubMed: www.ncbi.nlm.nih.gov/pubmed/8571094

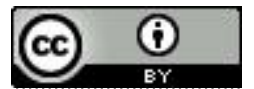




\title{
Risk assessment methodologies for carcinogenic compounds in indoor air
}

\author{
by Bjørn A Nexø, PhD'
}

\begin{abstract}
Nexø BA. Risk assessment methodologies for carcinogenic compounds in indoor air. Scand $J$ Work Environ Health 1995;21:376-81.

Objectives The purpose of this study was to compare different methods for calculating maximal allowable concentrations of potentially carcinogenic substances in indoor air. Benzene, tetrachloroethylene, trichloroethylene, and vinyl chloride were selected as the model substances.

Methods Estimates were used of carcinogenic potency from quantitative risk assessment, lowest observable effect levels (LOEL) from animal experiments and epidemiologic studies combined with safety factors, and estimation from occupational exposure limits with safety factors. The estimates were compared with actual concentrations in buildings in Denmark.

Results Concentrations of benzene, tetrachloroethylene, trichloroethylene, and vinyl chloride of the order of $10,20,200$, and $40 \mathrm{ppb}$, respectively, in indoor air were found to correspond to a $10^{-4}$ lifetime risk of cancer.

Conclusions The estimated maximal allowable concentrations of carcinogenic compounds obtained from indoor air by quantitative risk assessment using a lifetime risk of $10^{-4}$ or using LOEL values and suitable safety factors appear to be comparable and reasonable. Calculations based on occupational exposure limits and safety factors generally give comparable or somewhat higher values. Using a lifetime risk of $10^{-6}$ for quantitative risk assessment does not seem reasonable considering the risks associated with the activities of everyday life.
\end{abstract}

Key terms benzene, cancer, tetrachloroethylene, trichloroethylene, vinyl chloride.

Some chemicals can cause cancer. Of that we are sure. The fundamental questions of risk assessment are "How much of a given chemical does it take, and what percentage of the exposed population will be afflicted?" Moreover, if we cannot reduce the risk to zero, what is then an acceptable incidence of disease?

The sorry truth is that there are no scientifically satisfactory answers. The results presented are therefore not strict scientific truths, but rather attempts to apply what seems to be reasonable approaches.

The main problem is that cancer risk assessment is based on experiments with animals or on epidemiologic data which are then applied to situations that themselves are not experimentally accessible. It is thus necessary to make extrapolations, the validity of which cannot be established.

This paper deals with an evaluation of the risks associated with the presence of chemical substances in indoor air. Specifically, I have concerned myself with three substances that frequently occur as pollution on building grounds, namely, benzene, tetrachloroethylene and trichloroethylene. To complement these, I have also in- cluded vinyl chloride. Benzene and vinyl chloride have been classified by the International Agency for Research on Cancer as belonging to group 1 (ie, they are carcinogenic to humans). Tetrachloroethylene has been classified as belonging to group $2 \mathrm{~B}$ (ie, it is possibly carcinogenic to humans), while trichloroethylene has been classified as belonging to group 3 (ie, it is not classifiable as to its carcinogenicity to humans) (1).

The present problem is closely analogous to the evaluation of chemical risks at the workplace. There are some differences however. One is that people spend more time at home than at work. In addition, many people are likely to feel that home should be a safer place than work.

\section{Quantitative risk assessment}

Sometimes available epidemiologic data clearly show that a chemical can cause human cancer. To be truly useful, the data should also provide (i) accurate estimates of which concentrations of the chemical the population

1 National Institute of Occupational Health, Copenhagen, Denmark.

Requests for reprints to: Dr Bjørn Andersen Nexø National Institute of Occupational Health, Lersø Parkalle 105, DK-2100 Copenhagen $\varnothing$, Denmark. 
in question has been exposed to and for how long and (ii) a quantitative relation between exposure and risk.

Such information is only available for a few substances. But even when it exists, an important problem remains. Epidemiologic investigations are mostly made in a setting in which exposure is high, and consequently the cancer risk is relatively large, typically in selected workplaces. For use with indoor climate, the exposure time must be corrected. People normally spend approximately $40 \mathrm{~h}$ a week at work, but may spend close to $168 \mathrm{~h}$ a week indoors. In addition, the results must, in general, be extrapolated to "normal" doses of the chemical. How this should be done is controversial.

\section{Extrapolation of dose}

It is commonly assumed that no lower limit for the carcinogenicity of substances exists (ie, at low doses there is a linear relation between dose and risk). This assumption is based on the understanding that carcinogenic compounds act by damaging genetic material and that there is, in principle, no lower limit for when genetic damage can cause cancer. The model does not take the detoxification and repair mechanisms of the body into account, but it is probably the best that can be proposed for use at present. More realistic models will require information that is not available. A theoretical extension of the linearity at low doses leads to cancer-free subjects being an exponential function of a polynomium of the dose, so that in the simplest case

$$
P(d)=1-\exp \left(-q_{0}-q_{1} d\right),
$$

in which $\mathrm{P}(\mathrm{d})$ is the risk for cancer at dose $\mathrm{d}$ and $\mathrm{q}_{\mathrm{o}}$ and $\mathrm{q}_{\mathrm{I}}$ are positive constants. This formula leads to linearity in the low-dose region and to saturation at high doses, but has perhaps a tendency to overestimate cancer risk at low doses (2).

It is commonly assumed that the risk due to exposure to carcinogenic compounds is determined by the accumulated dose because the lasting outcome of genotoxic damage is somatic mutations and, once formed, they are not likely to disappear. I have also made this assumption when calculating the risk.

Some carcinogenic compounds may not act by damaging the genetic material. Rather, they induce growth in the target tissues, possibly in a way that especially favors cells that have already started to develop into cancer cells. For these so-called promoters one can expect a threshold value, a concentration under which the compound has no effect. However, it is difficult to establish whether a compound has a clean promoter effect. It is also difficult or impossible to calculate the threshold. Therefore, I have chosen to use the dose extrapolation in the preceding equation in all cases. The method will overestimate the risk at low doses if the compound is a promoter. Finally, the theoretical argument for using accumulated dose as the determinant of risk is weaker for promoters. However, there is good experimental evidence that promoters must be present for extended periods to exert their effect, and accumulated dose may thus be a reasonable measure to use after all.

Of the four compounds studied, benzene and vinyl chloride are genotoxic carcinogens, while tri- and tetrachloroethylene are probably mainly promoters.

\section{Extrapolation from animals to humans}

An additional problem arises in the common cases where only animal data are available for evaluating the risk of a compound. In these instances it is necessary to transform animal data to the human situation. This process can involve correction for different routes of administration of a compound, and it always involves a correction for different body sizes. A necessary underlying assumption is that the metabolism of the compound in animals and humans is qualitatively similar.

The simplest way to correct for body size is to calculate the dose per unit weight. Alternatively, one can standardize the dose relative to metabolism. The latter is roughly proportional to body weight raised to the power of 0.75 (smaller animals have a relatively faster metabolism). The difference between the two methods is approximately sevenfold when extrapolation is made from mice to humans. It is not clear which method should be preferred. One investigation indicates that the acute toxicity of numerous carcinogenic compounds is best standardized by metabolism (3). Another study, which is more inaccurate however, suggests that the carcinogenicity of certain compounds is better standardized by weight (4). I have chosen to use weight in the hope that any underestimation of the risk by this method is compensated by the overestimation arising from the extrapolation of the dose.

Applying the outlined methods to representative compounds produces the results shown in table 1 . It shows the concentrations in indoor air corresponding to various lifetime risks for cancer.

Table 1. Concentrations in indoor air and lifetime risks for cancer, as calculated by quantitative risk assessment.

\begin{tabular}{llll}
\hline Compound & \multicolumn{3}{c}{ Lifetime risk } \\
\cline { 2 - 4 } & \multicolumn{1}{c}{$4 \times 10^{-3}$} & \multicolumn{1}{c}{$10^{-4}$} & \multicolumn{1}{c}{$10^{-6}$} \\
\hline Benzene & $84-1160 \mathrm{ppb}$ & $2.1-29 \mathrm{ppb}$ & $0.02-0.29 \mathrm{ppb}$ \\
Tetrachloroethylene & $440-1520 \mathrm{ppb}$ & $11-38 \mathrm{ppb}$ & $0.11-0.38 \mathrm{ppb}$ \\
Trichloroethylene & $2.8-23 \mathrm{ppm}$ & $70-570 \mathrm{ppb}$ & $0.7-5.7 \mathrm{ppb}$ \\
Vinyl chloride & $1.6 \mathrm{ppm}$ & $39 \mathrm{ppb}$ & $0.39 \mathrm{ppb}$ \\
\hline
\end{tabular}

a The benzene calculations have been based on information from reference 5 the tetrachloroethylene calculations have been based on information from references 6 and 7; the trichloroethylene calculations are based on information from references 6,7 and 8 , and the vinyl chloride calculations have been based on information from reference 9 . 
Table 2. Lifetime risks associated with exposures and activities of normal life.

\begin{tabular}{lc}
\hline Event due to activity or exposure & Lifetime risk \\
\hline Cancer due to tobacco smoking & $10^{-1}$ \\
Fatal road accident & $10^{-2}$ \\
Cancer due to radon in indoor air & $4 \times 10^{-3}$ \\
Cancer due to passive smoking & $2 \times 10^{-3}$ \\
\hline
\end{tabular}

a The radon data have been taken from reference 10; the passive smoking data have been taken from reference 11.

The values for lifetime risks are not easily grasped intuitively. Therefore, I have compiled for comparison risks associated with various activities or exposures common in normal life in Denmark. The results are shown in table 2. It can be seen that the highest level of lifetime risk used in table 1 corresponds to current estimates of the risk for cancer due to radon in indoor air, while the two other risk levels are appreciably lower than any risks listed in table 2.

\section{Lowest observable effect levels and safety factors in risk assessment}

As an alternative to the quantitative risk assessment already outlined, the traditional toxicologic approach can be used, that is, determining a lowest observable effect level (LOEL) or no observable effect level (NOEL) from the experimental or epidemiologic data followed by a reduction of these levels by suitable safety factors. For carcinogenic compounds, it is customary to use a safety factor of 10 to get from LOEL to NOEL if NOEL is not available, a safety factor of 10 in the conversion of animal NOEL to humans is necessary, and a final safety factor of 10 to protect possible sensitive subpopulations among humans. The compound safety factor will thus be 1000, when one starts with a LOEL value for animals and 100 when starting with a LOEL value for humans. An additional factor of 4 may be relevant for occupational epidemiologic data for my purpose, namely, to correct for continuous exposure in indoor climates.

Tables 3 and 4 show the results of this approach when applied to the same four compounds used earlier. It is evident that the acceptable levels calculated are roughly similar to those corresponding to a lifetime risk of $10^{-4}$ in table 1. This result is perhaps not so odd. Because of the stochastic nature of cancer occurrence, it is generally not possible to define NOEL values with any accuracy, and one has to use LOEL values. In long-term animal experiments with cancer induction, group sizes are normally approximately 60 animals. If the cancer in question is relatively rare in the control group, a statistically significant result will occur when four to six extra animals get cancer in the treated group. Therefore the LOEL will correspond to a lifetime risk of roughly $10 \%$. When

Table 3. Maximal allowable concentrations in indoor air as calculated from the lowest observable effect levels (LOEL) on the basis of experimental animal data.

\begin{tabular}{|c|c|c|c|c|}
\hline Compound $^{\mathrm{a}}$ & $\begin{array}{l}\text { Exposure, } 5 \text { days } \\
\text { per week }\end{array}$ & $\begin{array}{l}\text { LOEL, observed } \\
\left(\mathrm{mg} \cdot \mathrm{kg}^{-1}\right)\end{array}$ & $\begin{array}{l}\text { LOEL, continuous } \\
\text { exposure for lifec } \\
\left(\mathrm{mg} \cdot \mathrm{kg}^{-1} \cdot \mathrm{d}^{-1}\right)\end{array}$ & $\begin{array}{c}\text { Maximal } \\
\text { allowable } \\
\text { concentrationd } \\
(\mathrm{ppb})\end{array}$ \\
\hline \multicolumn{5}{|l|}{ Benzene } \\
\hline $\begin{array}{l}\text { Rat } \\
\text { Mouse }\end{array}$ & $\begin{array}{l}\text { Inhalation } 6 \text { h per day, life } \\
\text { Gavage, life }\end{array}$ & $\begin{array}{l}29 \\
25\end{array}$ & $\begin{array}{l}21 \\
18\end{array}$ & $\begin{array}{l}23 \\
19\end{array}$ \\
\hline \multicolumn{5}{|c|}{ Tetrachloroethylene } \\
\hline Mouse & Gavage, life & 70 & 50 & 25 \\
\hline \multicolumn{5}{|c|}{ Trichloroethylene } \\
\hline $\begin{array}{l}\text { Mouse } \\
\text { Mouse }\end{array}$ & $\begin{array}{l}\text { Inhalation, life } \\
\text { Gavage, } 78 \text { weeks* }\end{array}$ & $\begin{array}{l}194 \\
287\end{array}$ & $\begin{array}{l}139 \\
154\end{array}$ & $\begin{array}{r}90 \\
100\end{array}$ \\
\hline \multicolumn{5}{|c|}{ Vinyl chloride } \\
\hline $\begin{array}{l}\text { Rat } \\
\text { Rat }\end{array}$ & $\begin{array}{l}\text { Inhalation } 6 \text { h per day, life } \\
\text { Gavage, } 52 \text { weeks* }\end{array}$ & $\begin{array}{l}2.3 \\
4.09\end{array}$ & $\begin{array}{l}1.64 \\
1.46\end{array}$ & $\begin{array}{l}2.3 \\
2\end{array}$ \\
\hline \multicolumn{5}{|c|}{$\begin{array}{l}\text { The data on benzene have been taken from reference } 5 \text {; the data on tetrachloroethylene have been taken from reference } 6 \text {; the data on } \\
\text { trichloroethylene have been taken from references } 7 \text { and } 12 \text {; and the data on vinyl chloride have been taken from references } 6 \text { and } 9 \text {. } \\
\text { The LOEL observed is the actual dose received on a day of experiment. For the gavage studies the value was taken directly from the respective } \\
\text { sources. For the inhalation studies the concentration in the air was multiplied by the ventilation }\left(6 \mathrm{I} \cdot \mathrm{h}^{-1} \text { for rats and } 1.8 \mathrm{l} \cdot \mathrm{h} \mathrm{h}^{-1} \text { for mice), }\right. \\
\text { multiplied by the exposure time }(6 \mathrm{~h}) \text {, and divided by the weight of the animals }(0.4 \mathrm{~kg} \text { for rats and } 0.03 \mathrm{~kg} \text { for mice). The calculation assumes } \\
\text { complete absorption of the inhaled substance. } \\
\text { c The LOEL continuous exposure for life is the corresponding value if animals were continuously exposed. It was calculated by multiplying the } \\
\text { LOEL observed by } 5 / 7 \text { to correct for the absence of exposure on weekends and, where relevant }\left(^{\star}\right) \text {, divided by a factor (1.33 and } 2 \text {, respectively) } \\
\text { to correct for limitations in the exposure period. } \\
\text { a The maximal allowable concentrations were calculated from the LOEL at continuous exposure by multiplying by } 70 \mathrm{~kg} \text { to correct for the weight } \\
\text { of humans, dividing by } 20 \mathrm{~m}^{3} \cdot \mathrm{d}^{-1} \text { to correct for human ventilation, dividing by a safety factor of } 1000 \text {, and converting to parts per billion. The } \\
\text { calculation assumes complete absorption of the inhaled substance. }\end{array}$} \\
\hline
\end{tabular}


combined with a safety factor of 1000 , the resulting concentration will correspond roughly to a lifetime risk of $10^{-4}$.

Correspondingly, in epidemiologic investigations, such studies will typically involve 1000 persons with an average exposure period of 10 to 20 years. Exposures typically occur in a work setting (ie, for approximately $40 \mathrm{~h}$ a week). Larger studies are possible but difficult to combine with the accurate exposure assessment necessary for determining the cumulative LOEL value. Therefore the typical epidemiologic study covers roughly 15000 person-years, of which one-fourth or 4000 person-years were spent at work. This value corresponds to 50 lives of continuous exposure. If a single case of an extremely rare cancer, a "signal cancer," occurs, it may be significant, but in general at least two or three cases are necessary for a significant result. Therefore, in the typical epidemiologic study in a workplace setting, the LOEL will correspond to a lifetime risk of roughly $4 \%$ with continuous exposure. The cumulative LOEL from occupational epidemiologic studies must be divided by a factor of 4 to correct for the limited time at the workplace. When combined with the safety factor, in this case 100 , the resulting concentration will correspond roughly to a lifetime risk of $10^{-4}$.

There is an interesting discrepancy between the maximal allowable concentrations calculated for vinyl chloride from animal and human data. The "human concentration" is almost 100-fold higher. This difference is probably due to several things. One is that the epidemiologic data for vinyl chloride only allow a very crude estimate for the LOEL, which is probably much higher than the true value. Second, many animal experiments have been performed, and they differ considerably in respect to the observed effective level. I have used one of the lowest values observed for table 3 .

\section{Estimation of maximal allowable concentrations from occupational exposure limits}

In a recent report (14) my colleague and I have argued that maximal allowable concentrations for noncarcinogenic compounds in indoor air can be derived from occupational exposure limits by reducing these values by a factor of 40 (14). The factor 40 was found by assuming that people spent roughly four times as much time at home than at work and multiplying by a factor of 10 to allow for sensitive subjects. Thus the calculation does not address the issue of lifelong cumulative effects. However, it does not seem unreasonable to apply the same rule to carcinogenic compounds. If the occupational exposure limit is set at a reasonable risk level, a reduction by 7 should then give a corresponding risk for indoor air
Table 4. Maximal allowable concentrations in indoor air as calculated from the lowest observable effect level (LOEL) on the basis of human epidemiologic data.

\begin{tabular}{|c|c|c|c|}
\hline Compounda & $\begin{array}{c}\text { Cumulative } \\
\text { LOEL, } \\
\text { (ppm x year) }\end{array}$ & $\begin{array}{l}\text { LOEL } \\
\text { at continuous } \\
\text { exposure } \\
\text { for life } \\
\text { (ppm) }\end{array}$ & $\begin{array}{c}\text { Maximal } \\
\text { allowable } \\
\text { concentration } \\
(p p b)\end{array}$ \\
\hline $\begin{array}{l}\text { Benzene } \\
\text { Vinyl chloride }\end{array}$ & $\begin{array}{r}300 \\
4400\end{array}$ & $\begin{array}{l}1.1 \\
16\end{array}$ & $\begin{array}{r}11 \\
160\end{array}$ \\
\hline \multicolumn{4}{|c|}{$\begin{array}{l}\text { The data on benzene have been taken from table } 2 \text { of reference } 13 \text {, } \\
\text { and the data on vinyl chloride have been taken from reference } 9 \text {. } \\
\text { b The cumulative LOEL from occupational epidemiologic studies was } \\
\text { converted to the LOEL at continuous exposure by dividing it by } 4 \text { to } \\
\text { correct for a workday of } 8 \text { hours and } 5 \text { days a week at work, and by } \\
\text { dividing it by } 70 \text { years to correct for lifelong exposure. }\end{array}$} \\
\hline
\end{tabular}

(a factor of 4 to correct for limited hours a week at the workplace and a factor of 1.75 to correct for the time of life spent at work). The residual factor of 6 may be interpreted as ensuring that home is a safer place than work.

It should be noted that this method is a shortcut, rather than an independent approach for determining maximally allowable concentrations in indoor air. The toxicologic data forming the basis for the determination of occupational exposure limits are in all likelihood the same as those used with other methods.

Table 5 shows the maximally allowable concentrations that are derived when this approach is applied to Danish occupational exposure limits. When the results are compared with those of table 1 , it is clear that the maximally allowed concentrations derived for vinyl chloride and trichloroethylene roughly correspond to a lifetime risk of $10^{-4}$. The same applies to benzene if the new notified occupational exposure limit is used. In the case of tetrachloroethylene the value approaches a lifetime risk of $4 \times 10^{-3}$. In fact, I suspect that the occupational exposure limit for tetrachloroethylene was not set from its carcinogenic properties, but rather from its neurotoxicity. When I compare the values of table 5 with those of table 3 , it is clear that the values derived from occupational exposure limits in general are higher than those derived from LOEL values from animal studies. The

Table 5. Maximal allowable concentrations in indoor air, as derived from Danish occupational exposure limits.

\begin{tabular}{lcc}
\hline Compound & $\begin{array}{l}\text { Occupational exposure } \\
\text { limit, Denmark } \\
(\mathrm{ppm})\end{array}$ & $\begin{array}{c}\text { Maximal } \\
\text { allowable } \\
\text { concentration } \\
(\mathrm{ppb})\end{array}$ \\
\hline Benzene & 5 (in operation) & 125 \\
Tetrachloroethylene & 0.1 (notified) & 2.5 \\
Trichloroethylene & 10 (in operation) & 250 \\
Vinyl chloride & 10 (in operation) & 250 \\
\hline
\end{tabular}

Scand J Work Environ Health 1995, vol 21, no 5 
exception is the value derived from the new notified occupational exposure limit for benzene.

\section{Actual concentrations in indoor air}

The National Housing and Building Agency in Denmark recently published measurements of actual concentrations of a series of compounds in houses assumed to be safe (ie, there was no suspicion or indication that the houses were built on contaminated soil) (15). Among the compounds studied were benzene, tetrachloroethylene, and trichloroethylene. The median concentrations and ranges of values for these compounds are shown in table 6 . It is interesting to compare these observed levels with the previous results. Essentially all the houses meet the requirements formulated from LOEL values from animals and the values formulated from the occupational exposure limits. The major exception is the maximal allowable concentration derived from the new notified occupational exposure limit for benzene, which a minority of the houses cannot meet. In addition, essentially all of the houses meet the requirements calculated as corresponding to a lifetime risk of $10^{-4}$. However, if one uses levels corresponding to a lifetime risk of $10^{-6}$, none of the houses can meet the requirement for benzene, none of the houses can meet the requirement for tetrachloroethylene, and only a minority of the houses can meet the requirement for trichloroethylene. In fact, not even ambient air in rural areas $(0.3-3 \mathrm{ppb})$ can meet the requirement for benzene $(5)$.

It is perhaps worthwhile to calculate the approximate expected gain of enforcing a maximal acceptable lifetime risk of $10^{-6}$. If the concentrations listed in table 6 are representative for houses in Denmark in general and if the geometric means of the concentration intervals listed in table 1 are used, it can be concluded that, in Denmark, approximately one case of cancer is caused by benzene in indoor air per year, two cases of cancer are caused by tetrachloroethylene in indoor air, and 0.3 cases of cancer are caused by trichloroethylene in indoor air. If one knows how to reduce the concentrations of the three compounds so that they correspond to a lifetime risk level of $10^{-6}$, then these three to four cancers per year

Table 6. Concentrations of various compounds in indoor air in ordinary Danish houses.

\begin{tabular}{lcc}
\hline Compound & $\begin{array}{c}\text { Median } \\
\text { concentration } \\
(\mathrm{ppb})\end{array}$ & $\begin{array}{c}\text { Range of } \\
\text { concentrations } \\
(\mathrm{ppb})\end{array}$ \\
\hline Benzene & 1.4 & $0.9-25$ \\
Tetrachloroethylene & 7 & $2-12$ \\
Trichloroethylene & 11 & $2.8-22$ \\
\hline
\end{tabular}

could be prevented. However, approximately 10 people die each year in the current building activities in Denmark. I venture that more than three to four lives per year would be lost for a considerable period by modifying or rebuilding all houses in Denmark. It may only be worthwhile to modify existing buildings when the compounds exceed current average levels in indoor air by a certain margin.

\section{Concluding remarks}

Maximal allowable concentrations for benzene, tetrachloroethylene, trichloroethylene, and vinyl chloride are similar when they are calculated by quantitative risk assessment as corresponding to a lifetime risk of $10^{-4}$ or they are calculated from LOEL values in animal experiments with a safety factor of 1000 . Calculation by using LOEL values from epidemiologic data with a safety factor of 100 also seemed to give similar values if the epidemiologic study included a careful estimation of exposure to allow for an accurate determination of the LOEL. I expect these statements to be applicable to many other compounds also.

Estimating maximal allowable concentrations in indoor air as being one-fortieth of the corresponding occupational exposure limit also seems a feasible approach. However, some variability in the results exists, relative to those obtained by the other two methods. This difference is perhaps not so surprising, as many considerations other than the safety aspect goes into the setting of an occupational exposure limit.

Using a lifetime risk of $10^{-6}$ in quantitative risk assessment does not seem reasonable, as many risks of everyday life exceed this level by many orders of magnitude. It will only be worthwhile if the cost of achieving such a level is small. In the present case, official acceptance of a lifetime risk of $10^{-6}$ for carcinogenic compounds in indoor air would have the consequence of outlawing living in most, if not all, buildings in Denmark.

Calculating maximal allowable concentrations of carcinogenic compounds in indoor air by quantitative risk assessment using a lifetime risk of $10^{-4}$ or by using LOEL values and suitable safety factors appears to give comparable and reasonable results.

\section{Acknowledgments}

The author is indebted to Drs Gunnar Damgaard Nielsen and Leif Simonsen for their fruitful discussions and for critically reading the manuscript. 
This work was supported financially by The National Housing and Building Agency and by the Danish Technical Research Council as part of the research program "Healthy Buildings" 1993-1997.

\section{References}

1. International Agency for Research on Cancer (IARC). Overall evaluation of carcinogenicity: an updating of IARC monographs volumes 1 to 42. Lyon: IARC, 1987. IARC monographs on the evaluation of carcinogenic risks to humans, suppl 7.

2. Johannsen FR. Risk assessment of carcinogenic and noncarcinogenic chemicals. CRC Crit Rev Toxicol 1990;20:341 - 67.

3. Travis CC, White RK. Interspecific scaling of toxicity data Risk Anal 1988;8:119-25.

4. Allen BC, Crump KS, Shipp AM. Correlation between carcinogenic potency of chemicals in animals and humans. Risk Anal 1988;8:531-44.

5. Neumeier G. Occupational exposure limits: criteria document for benzene. Luxembourg: Commission of the European Communities, 1993. EUR 14491.

6. Gold LS, Sawyer CB, Magaw R, Backman GM, de Veciana $M$, Levinson $\mathrm{R}$, et al. A carcinogenic potency database of the standardized results of animal bioassays. Environ Health Perspect 1984;58:9-319.

7. Gold LS, Slone TH, Backman GM, Magaw R, Da Costa M, Lopipero R, et al. Second chronological supplement to the carcinogenic potency database: standardized results of animal bioassays published through December 1984 and by the na- tional toxicology program through may 1986. Environ Health Perspect 1987;74:237 -329.

8. Gold LS, Slone TH, Backman GM, Eigenberg S, Da Costa M, Wong $\mathrm{M}$, et al. Third chronological supplement to the carcinogenic potency database: standardized results of animal bioassays published through December 1986 and by the national toxicology program through June 1987. Environ Health Perspect 1990;84:215-85.

9. Anonymous. A scientific basis for risk assessment of vinyl chloride. Regul Toxicol Pharmacol 1987;7:120-7.

10. Anonymous. Radon-boliger-strålingsdosis-lungekræftrisiko [Radon-housing-radiation dose-risk of lung cancer]. Copenhagen: National Board of Health, 1987.

11. Repace JL, Lowrey AH. Risk assessment methodologies for passive smoking-induced lung cancer. Risk Anal 1990;10: 27-37.

12. Bogen KT. Pharmacokonetics for regulatory risk analysis: the case of trichloroethylene. Regul Toxicol Pharmacol 1988; $8: 447-66$.

13. Rinsky RA, Smith AB, Hornung R, Filloon TG, Young RJ, Okun $\mathrm{AH}$, et al. Benzene and leukemia: an epidemiological risk assessment. N Engl J Med 1987;316:1044-50.

14. Nexø BA, Nielsen GD. Toksikologisk vurdering af indeklimaforureninger [Toxicological evaluations of indoor pollution]. Copenhagen: National Housing and Building Agency, 1993.

15. Anonymous. Baggrundsverdier for organiske forbindelser i indeluften [Background values for organic compounds in indoor air]. Copenhagen: National Housing and Building Agency, 1994.

Received for publication: 2 December 1994 